\title{
Interaction of rosiglitazone and pioglitazone with organic cation transporters
}

\author{
Sirima Soodvilai $^{\mathrm{a}}$, Chatchai Muanprasat $^{\mathrm{b}, \mathrm{c}}$, Varanuj Chatsudthipong $^{\mathrm{b}, \mathrm{c}}$, Sunhapas Soodvilai ${ }^{\mathrm{b}, \mathrm{c}, *}$ \\ a Department of Pharmaceutical Technology, Faculty of Pharmacy, Rangsit University, Pathumthani, Thailand \\ b Department of Physiology, Faculty of Science, Mahidol University, Bangkok, Thailand \\ c Research Centre of Transport Protein for Medical Innovation, Faculty of Science, Mahidol University, \\ Bangkok, Thailand
}

*Corresponding author, e-mail: sunhapas.soo@mahidol.ac.th

Received 12 Nov 2012

Accepted 9 Apr 2013

\begin{abstract}
Thiazolidinedione drugs (TZDs) are used in the treatment of type 2 diabetes mellitus (DM). This study aimed to investigate the potential influence of TZDs on organic cation transporters (OCTs). Such interactions were examined using Chinese hamster ovary (CHO-K1) cells stably and singly transfected with rabbit (rb)OCT1 and rbOCT2, and in cells that endogenously express OCT1 (HepG2 cells) and OCT2 (LLC-PK1 cells). Rosiglitazone but not pioglitazone inhibited OCT1and OCT2-mediated ${ }^{3} \mathrm{H}-\mathrm{MPP}^{+}$uptake with half maximal inhibitory concentration $\left(\mathrm{IC}_{50}\right)$ of $7.4 \pm 1.2 \mu \mathrm{M}$ and $2.5 \pm 0.4 \mu \mathrm{M}$, respectively. The mode of inhibition by rosiglitazone was further determined using kinetic analysis. We showed that rosiglitazone decreased the maximal transport $\left(V_{\max }\right)$ without affecting the transporter affinity $\left(K_{\mathrm{m}}\right)$, indicating that the inhibitory effect of rosiglitazone on OCT1 and OCT2 entails a noncompetitive mechanism. Similarly, the inhibitory effect of rosiglitazone on $\mathrm{MPP}^{+}$uptake was observed in OCT1 and OCT2 endogenously expressed. We conclude that rosiglitazone may inhibit transport activity of OCT1 and OCT2 by interfering with a non-substrate-binding site on the transporters. Since rosiglitazone is used in combination with other drugs to treat DM-related diseases, its inhibitory effect on OCTs may influence the pharmacokinetic of cationic drugs.
\end{abstract}

KEYWORDS: liver, kidney, drug-drug interaction, diabetes, PPAR $\gamma$

\section{INTRODUCTION}

Thiazolidinedione drugs (TZDs) including rosiglitazone and pioglitazone are used in the treatment of type 2 diabetes mellitus (DM) patients ${ }^{1-5}$. TZDs act as insulin sensitizers by activating of peroxisome proliferator-activated receptor gamma (PPAR $\gamma)$, a member of the nuclear receptor subfamily. PPAR $\gamma$ activation by TZDs improves insulin sensitivity in liver, adipose tissue, and skeletal muscle ${ }^{6,7}$. TZDs are not commonly used as a first-line therapy but they are widely used in combination regimens, particularly in patients who do not respond to the conventional treatment regimens ${ }^{2}$. It has been reported that TZDs are used in combination with sulphonylurea, metformin, meglitinide, and $\alpha$-glucosidase inhibitor for treatment of diabetes ${ }^{8}$. Hence it is possible that drug-drug interaction between TZDs and other antihyperglycaemic agents may lead to alternation in their pharmacokinetics as well as alterations in treatment efficacy and adverse effects. In addition, management of type $2 \mathrm{DM}$ usually requires polypharmacy therapy to treat concurrent complications such as dyslipidemia and hypertension ${ }^{8,9}$, TZDs-drug interaction should be identified to help to control those conditions.

Organic cation transporters (OCTs) including OCT1 (SLC22A1) and OCT2 (SLC22A2) mainly express in liver and kidney, respectively, where they are localized in the basolateral membrane of cells, and uptake cationic compounds into the cells ${ }^{10}$. Basolateral uptake of organic cations into the cell by OCTs is driven by an inside-negative electrical potential difference ${ }^{10,11}$. These transporters are responsible for detoxification and elimination of xenobiotics from systemic circulation, and thus they are an important determinant of drugs efficacy and toxicity ${ }^{10,12-14}$. It has been reported that OCT1 and OCT2 mediate excretion of therapeutic cationic drugs such as antihyperglycaemic drug (metformin) and antihypertensive drugs such as beta-blockers ${ }^{15-17}$. Since the management of type 2 DM patients involves combined pharmaceutical drugs therapy, we investigated the potential influence of OCTs on TZDs-drug interaction. The interaction and mechanism of rosiglitazone and pioglitazone, with OCT1 and OCT2 were determined in heterologous and endogenous expressing system. 


\section{MATERIALS AND METHODS}

\section{Chemicals}

Radiolabelled methyl-4-phenylpyridinium acetate $\left({ }^{3} \mathrm{H}-\mathrm{MPP}^{+}\right)$was purchased from American Radiolabeled Chemical Inc. Rosiglitazone and pioglitazone were purchased from Cayman Chemical. Other chemicals were obtained from various sources with highest purity available.

\section{Cell culture}

rbOCT1 and rbOCT2 transfected in CHO-K1 cells were kindly provided by Prof. Stephen H. Wright (Dept. of Physiology, Univ. of Arizona, USA), HepG2 cells, and LLC-PK1 cells were obtained from the American Type Culture Collection. The transfected CHO-K1 cells were cultured in F12 Ham Kaighn's modification $(\mathrm{F} 12 \mathrm{~K})$ medium whereas HepG2 and LLC-PK1 cells grown in Dulbecco's Modified Eagle Medium (DMEM). Both media were supplemented with $10 \%$ FBS and $100 \mathrm{U} / \mathrm{ml}$ penicillin and $100 \mu \mathrm{g} / \mathrm{ml}$ streptomycin and were incubated at $37^{\circ} \mathrm{C}$ in a humidified $5 \% \mathrm{CO}_{2}$, and $95 \%$ air atmosphere.

\section{Transport assay in cell culture studies}

The cells were grown in a 24-well plate for $48 \mathrm{~h}$ followed twice washed with Dulbecco's modified phosphate-buffered saline (D-PBS) $(\mathrm{NaCl} 137 \mathrm{mM}$, $\mathrm{KCl} 3 \mathrm{mM}, \mathrm{Na}_{2} \mathrm{HPO}_{4} 0.5 \mathrm{mM}, \mathrm{KH}_{2} \mathrm{PO}_{4} 1 \mathrm{mM}$, $\mathrm{MgCl}_{2} 0.5 \mathrm{mM}, \mathrm{CaCl}_{2} 1 \mathrm{mM}$, D-glucose $5.6 \mathrm{mM}$ at $\mathrm{pH}$ 7.4) and were incubated at $37^{\circ} \mathrm{C}$ for further $30 \mathrm{~min}$. After a preincubation period, accumulation of ${ }^{3} \mathrm{H}_{-\mathrm{MPP}^{+}}$was determined by incubating the cell with D-PBS containing $10 \mathrm{nM}{ }^{3} \mathrm{H}-\mathrm{MPP}^{+}$for $1 \mathrm{~min}$ (initial rate transport) at $37^{\circ} \mathrm{C}$. The uptake was stopped by removing the transport buffer, followed by three times washing with ice-cold D-PBS containing $1 \mathrm{mM}$ unlabelled $\mathrm{MPP}^{+}$. The cells were solubilized overnight with $10 \%$ SDS in $0.4 \mathrm{~N} \mathrm{NaOH}$, neutralized with $\mathrm{HCl}$. The accumulated ${ }^{3} \mathrm{H}-\mathrm{MPP}^{+}$was measured by liquid scintillation beta counter (1214 Rackbeta, LKB Wallac, Sweden). The OCT-mediated $\mathrm{MPP}^{+}$transport was calculated from subtraction of total transport by transport in mock cells.

\section{Kinetics of OCT-mediated ${ }^{3} \mathrm{H}-\mathrm{MPP}^{+}$transport}

The half inhibitory concentrations $\left(\mathrm{IC}_{50}\right)$ of rosiglitazone for OCT-mediated $\mathrm{MPP}^{+}$uptake was examined by incubating the cells with D-PBS containing radioactive medium $\left(10 \mathrm{nM}\right.$ of $\left.{ }^{3} \mathrm{H}-\mathrm{MPP}^{+}\right)$plus varying concentrations of rosiglitazone for $1 \mathrm{~min}$. The $\mathrm{IC}_{50}$ values were estimated using nonlinear regression analysis with GraphPad Prism. In addition, the kinetic parameters of $\mathrm{MPP}^{+}$transport by OCTs in the presence of $10 \mu \mathrm{M}$ rosiglitazone were determined using nonlinear regression analysis to fit the MichaelisMenten kinetic equation:

$$
V=V_{\max } \frac{[\mathrm{S}]}{K_{\mathrm{m}}+[\mathrm{S}]}
$$

where $V$ is the rate of $\mathrm{MPP}^{+}$uptake, $V_{\max }$ is the maximum rate of $\mathrm{MPP}^{+}$uptake, $K_{\mathrm{m}}$ is the $\mathrm{MPP}^{+}$ concentration that results in half-maximum transport (Michaelis-Menten constant), and [S] is the concentration of $\mathrm{MPP}^{+}$in the transport reaction.

\section{Statistical analysis}

Data are shown as means \pm S.E. and $n$ represents the number of experiments. In each experiment, a minimum of three wells was used to generate each data point for cell culture studies. Statistical differences were assessed by using Student's $t$-test and oneway ANOVA (using GraphPad Prism software, La Jolla, CA). A significant level of differences were considered as statistical significance when $p<0.05$.

\section{RESULTS}

\section{cis-Effect of TZDs on OCT1- and OCT2-mediated ${ }^{3} \mathrm{H}-\mathrm{MPP}^{+}$uptake}

To determine whether TZDs interact with OCT1 and OCT2, we investigated the cis-effect of rosiglitazone and pioglitazone on OCT-mediated ${ }^{3} \mathrm{H}-\mathrm{MPP}^{+}$uptake in the OCT1 and OCT2 expressing CHO-K1 cells. Cells were incubated with transport buffer containing radioactive medium alone (control) or in the presence of $100 \mu \mathrm{M}$ rosiglitazone or pioglitazone for $1 \mathrm{~min}$. As shown in Fig. 1, rosiglitazone significantly decreased

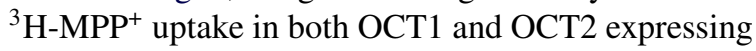
cells compared with the control. However, pioglitazone produced a slightly inhibitory effect in OCT2 expressing cells but had no effect on OCT1 expressing cells.

\section{Concentration dependent of inhibitory effect of rosiglitazone on ${ }^{3} \mathrm{H}-\mathrm{MPP}^{+}$uptake}

Rosiglitazone showed inhibitory effect on transport of $\mathrm{MPP}^{+}$, the inhibitory potency of rosiglitazone was further determined. As shown in Fig. 2, rosiglitazone inhibited OCT1- and OCT2-mediated ${ }^{3} \mathrm{H}-\mathrm{MPP}^{+}$uptake in a concentration-dependent manner over the concentration range of $1 \mu \mathrm{M}$ to $100 \mu \mathrm{M}$. The $\mathrm{IC}_{50}$ values of rosiglitazone for OCT1 and OCT2 were $7.4 \pm 1.2 \mu \mathrm{M}$ and $2.5 \pm 0.4 \mu \mathrm{M}$, respectively. 

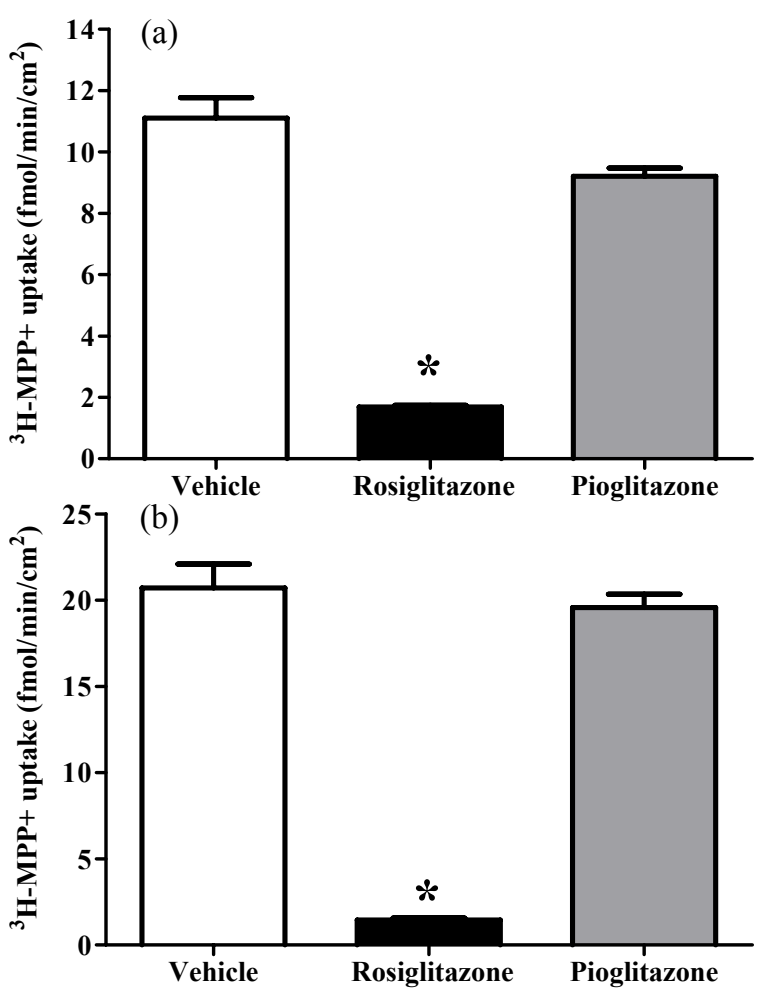

Fig. 1 cis-Effect of TZD drugs on OCT-mediated ${ }^{3} \mathrm{H}$ $\mathrm{MPP}^{+}$uptake in CHO-K1 cells expressing (a) OCT1 or (b) OCT2. CHO-K1 cells singly expressing OCT1 or OCT2 were incubated with ${ }^{3} \mathrm{H}-\mathrm{MPP}^{+}$alone, or in the presence of $100 \mu \mathrm{M}$ of rosiglitazone or pioglitazone for $1 \mathrm{~min}$ and then the radiolabelled accumulation of ${ }^{3} \mathrm{H}-\mathrm{MPP}^{+}$in the cells was determined using liquid scintillation counting. The uptake data represent OCT-mediated after subtraction of the total value from mock cells. The uptakes of ${ }^{3} \mathrm{H}_{-} \mathrm{MPP}^{+}$ were calculated from at least 3 independent experiments and expressed as $\mathrm{fmol} / \mathrm{min} / \mathrm{cm}^{2}$. $* p<0.05$ compared to control.

\section{Mechanism by which rosiglitazone inhibited OCT-mediated ${ }^{3} \mathrm{H}-\mathrm{MPP}^{+}$uptake}

The mode of rosiglitazone inhibition was characterized using kinetic analysis; Eadie-Hofstee plot analysis was performed. Fig. 3 showed that rosiglitazone decreased y-intercept of Eadie-Hofstee plot, but its slope was not influenced. Furthermore, the $V_{\max }$ of OCT1-mediated $\mathrm{MPP}^{+}$uptake in the presence of rosiglitazone was significantly decreased compared to the control value (control, $26.1 \pm 2.0 \mathrm{pmol} / \mathrm{min} / \mathrm{cm}^{2}$; with rosiglitazone, $15.1 \pm 1.2 \mathrm{pmol} / \mathrm{min} / \mathrm{cm}^{2}$ ). The result of OCT2-mediated $\mathrm{MPP}^{+}$transport showed a similar tendency to OCT1, the $V_{\max }$ of OCT2mediated ${ }^{3} \mathrm{H}-\mathrm{MPP}^{+}$was significantly decreased by
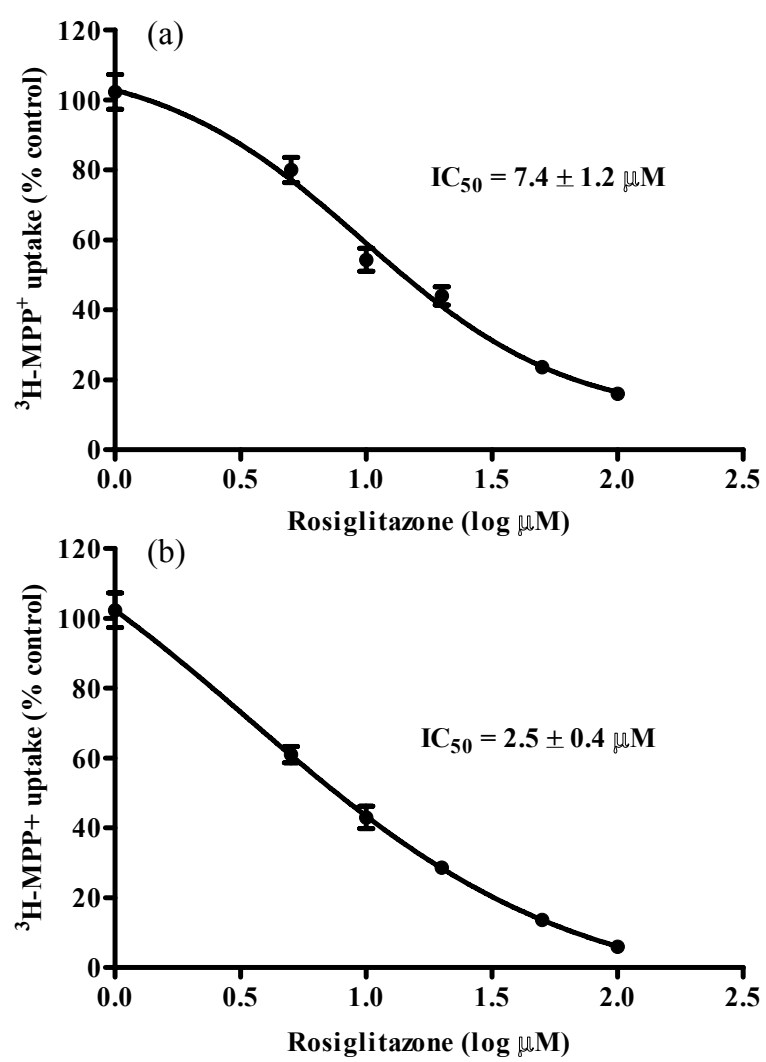

Fig. 2 Inhibitory potency of rosiglitazone on ${ }^{3} \mathrm{H}_{-} \mathrm{MPP}^{+}$ uptakes. (a) OCT1 expressing CHO-K1 cells or (b) OCT2 expressing $\mathrm{CHO}-\mathrm{K} 1$ cells were exposed to medium containing ${ }^{3} \mathrm{H}-\mathrm{MPP}^{+}$alone, or in the presence of various concentrations of rosiglitazone for $1 \mathrm{~min}$ followed by measurement of ${ }^{3} \mathrm{H}-\mathrm{MPP}^{+}$accumulation. The uptake of ${ }^{3} \mathrm{H}$ $\mathrm{MPP}^{+}$were represented only OCT-mediated transport after subtraction of total transport from mock cells and shown as percentage of control (no tested drugs). The $\mathrm{IC}_{50}$ values were calculated from uptake measured in triplicate from 3 independent experiments. The unit of $x$-axis is the log value of rosiglitazone concentrations $(\mu \mathrm{M})$.

rosiglitazone (control, $45.6 \pm 3.0 \mathrm{pmol} / \mathrm{min} / \mathrm{cm}^{2}$; with rosiglitazone, $25.9 \pm 2.0 \mathrm{pmol} / \mathrm{min} / \mathrm{cm}^{2}$ ). In contrast to $V_{\max }$, the $K_{\mathrm{m}}$ values of OCT1 and OCT2 were not influenced by rosiglitazone.

\section{Effect of rosiglitazone on OCT-mediated ${ }^{3} \mathrm{H}-\mathrm{MPP}^{+}$ uptake in HepG2 cells and LLC-PK1 cells}

We further examined the inhibitory effect of rosiglitazone on OCT transport function in HepG2 and LLC-PK1 cells that endogenously express OCT1 and OCT2, respectively. HepG2 cells and LLC-PK1 cells were incubated with medium containing ${ }^{3} \mathrm{H}-\mathrm{MPP}^{+}$ alone or plus $10 \mu \mathrm{M}$ rosiglitazone for $1 \mathrm{~min}$ followed 

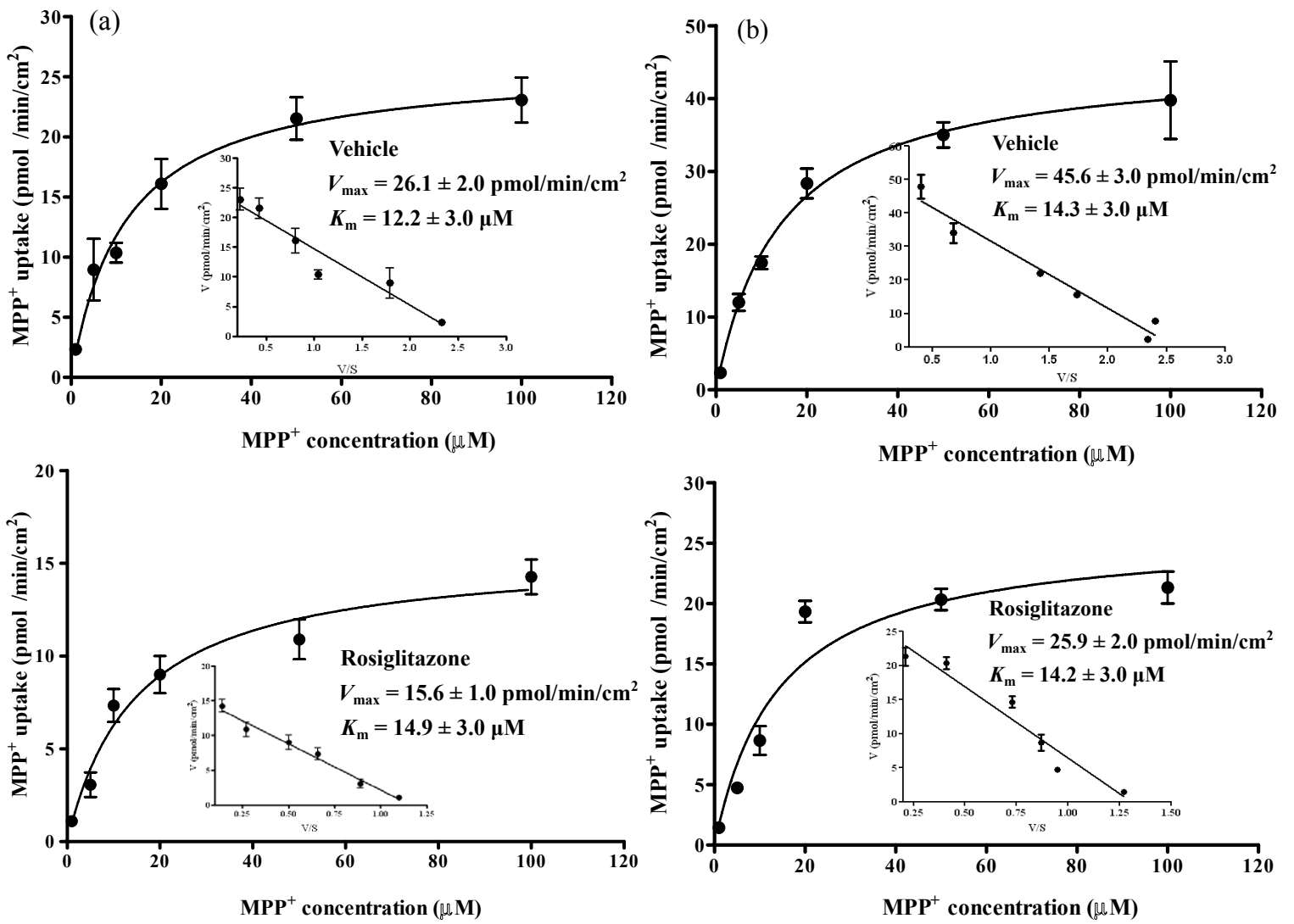

Fig. 3 Effect of rosiglitazone on kinetics of OCT-mediated ${ }^{3} \mathrm{H}-\mathrm{MPP}^{+}$transport. CHO-K1 cells transfected with (a) OCT1 or (b) OCT2 were incubated with various concentration of $\mathrm{MPP}^{+}$for $1 \mathrm{~min}$ in the absence or presence of $10 \mu \mathrm{M}$ rosiglitazone. The uptake of $\mathrm{MPP}^{+}$was calculated as $\mathrm{fmol} / \mathrm{min} / \mathrm{cm}^{2}$ of the confluent monolayer surface after subtraction of the total uptake from mock cells. The kinetic parameters were calculated by equation of Michaelis-Menten as mentioned in the text and were expressed as means \pm S.E. from 3 independent experiments. ${ }^{*} p<0.05$ compared to vehicle.

measurement of ${ }^{3} \mathrm{H}-\mathrm{MPP}^{+}$accumulation in the cells. As shown in Fig. 4, uptakes of ${ }^{3} \mathrm{H}-\mathrm{MPP}^{+}$into both cell types were significantly inhibited by rosiglitazone. Furthermore, the $\mathrm{IC}_{50}$ of rosiglitazone on ${ }^{3} \mathrm{H}-\mathrm{MPP}^{+}$ transport in HepG2 cells and LLC-PK1 cells were $11.9 \pm 2.3 \mu \mathrm{M}$ and $4.0 \pm 1.5 \mu \mathrm{M}$, respectively. As expected, the uptakes of ${ }^{3} \mathrm{H}-\mathrm{MPP}^{+}$into the cells were not affected by the presence of pioglitazone at high concentration.

\section{DISCUSSION}

Rosiglitazone maleate and pioglitazone hydrochloride are prescribed in patients with type 2 diabetes mellitus. These patients require a pharmacological therapy combination to maintain the plasma glucose level and to treat diabetes-related diseases such as hyperlipidemia and hypertension ${ }^{8}$. Hence drug-drug interactions should be addressed in patients who receive polypharmacy regimen. In this study, we examined the interaction of rosiglitazone and pioglitazone with OCT1 and OCT2, transporters responsible for clearance of cationic drugs from the body. Our data clearly demonstrates that rosiglitazone inhibits the uptake of ${ }^{3} \mathrm{H}-\mathrm{MPP}^{+}$, a prototypic substrate of OCT1 and $\mathrm{OCT} 2^{13}$, in a concentration-dependent manner. Surprisingly, pioglitazone showed no interaction with either transporters. This data may be supported by clinical evidence showing that pioglitazone has low potential of drug interaction with other drugs used in diabetes $^{8,18}$.

We investigated the inhibitory effect of rosiglitazone further. The inhibitory potency of rosiglitazone for OCT2 was found to be higher than that of OCT1 as shown by the lower $\mathrm{IC}_{50}$ value. In addition, the mechanism of OCT1 and OCT2 inhibition by rosiglitazone was determined from kinetic parameters of OCT-mediated $\mathrm{MPP}^{+}$transport. As evidence showing that rosiglitazone decreased $V_{\max }$ but not $K_{\mathrm{m}}$ of both transporters, it appeared that the inhibitory effects of rosiglitazone on OCT1 and OCT2 were mediated 

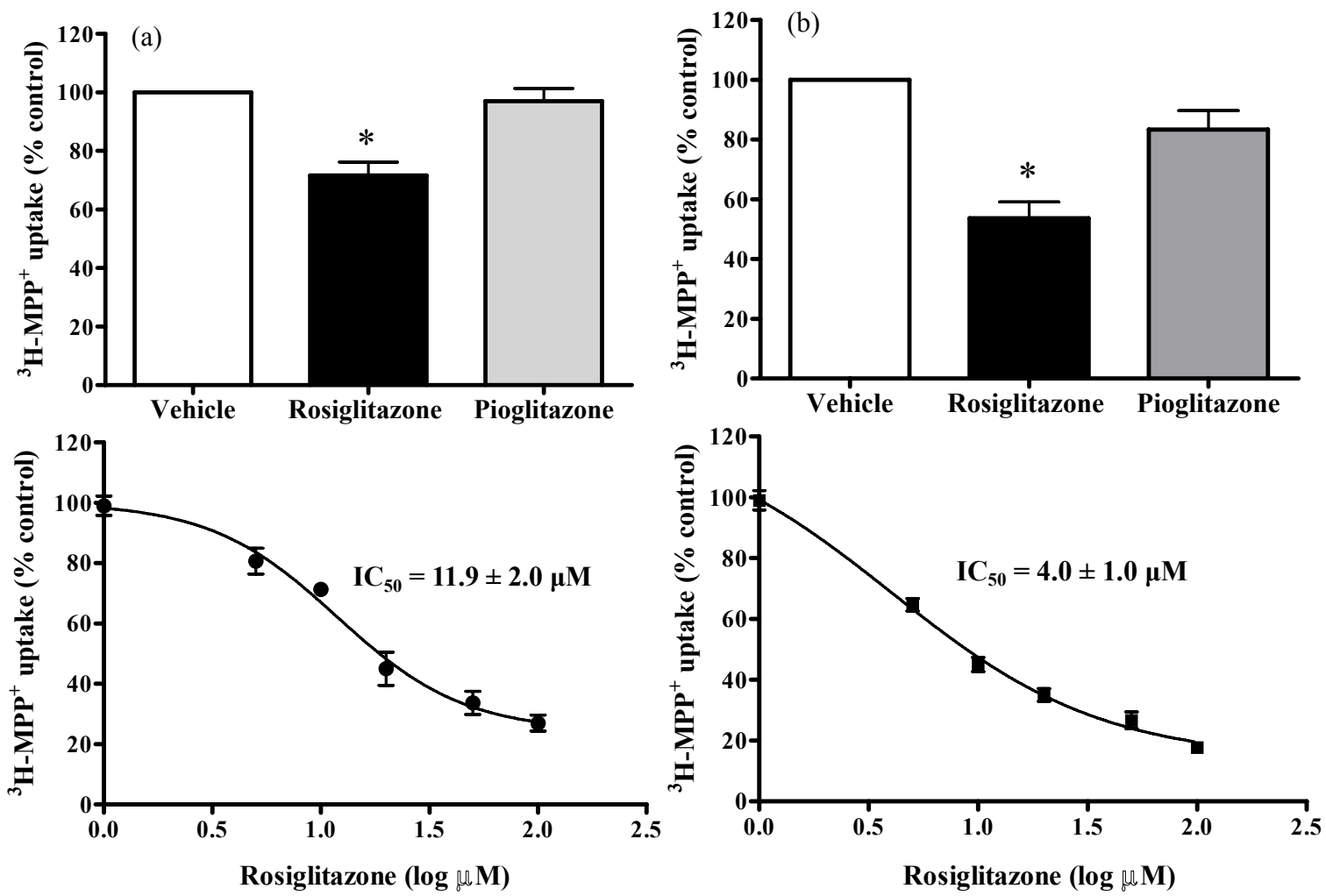

Fig. 4 Effect of rosiglitazone and pioglitazone on ${ }^{3} \mathrm{H}-\mathrm{MPP}^{+}$uptake in (a) HepG2 cells and (b) LLC-PK1 cells. The cells were incubated with ${ }^{3} \mathrm{H}-\mathrm{MPP}^{+}$alone or in the presence of $10 \mu \mathrm{M}$ rosiglitazone or $100 \mu \mathrm{M}$ pioglitazone for 1 min, and then the accumulation of radioactivity was determined as mentioned in the text. All data were calculated then expressed as $\%$ control and each data point represents the mean \pm S.E. of uptake measured from 3 independent experiments. $* p<0.05$ compared to control.

via non-competitive mechanism. It is possible that the inhibitory effect of rosiglitazone on $\mathrm{MPP}^{+}$uptake might be mediated via binding of rosiglitazone with transporters, then immobilization of the transporters, leading to inhibition of the transport activity with itself not entering the cells. Recent study demonstrated that OCT2 contains several binding sites for organic cations as evidence showing that TEA and $\mathrm{MPP}^{+}$ interacted with OCT2 via different binding sites ${ }^{19}$. Since $\mathrm{MPP}^{+}$was used as a marker for monitoring OCT transport activity, therefore, we could not rule out the possibility that rosiglitazone could be a substrate of OCT by interacting with the transporters via non $\mathrm{MPP}^{+}$binding site such as TEA binding site. However, this hypothesis need to be further investigated.

The interactions of rosiglitazone with OCT1 and OCT2 found in heterologous expressing cell were verified in HepG2 cells and LLC-PK1 cells that endogenously express OCT1 and OCT2, respectively ${ }^{20-22}$. Our data demonstrated the similar inhibitory effect of rosiglitazone on organic cation transport in the endogenously expressing system of OCTs whereas pioglitazone produced no effect. These data confirmed that rosiglitazone inhibited OCT-mediated organic compounds transport.

Since OCTs are the major determinant of cationic drug pharmacokinetics, inhibition of OCT activity by rosiglitazone could decrease body clearance of these drugs. Rosiglitazone might increase the plasma level of cationic drugs frequently used in type $2 \mathrm{DM}$ or DM-related conditions/diseases that are eliminated by OCTs such as metformin and beta-blockers ${ }^{15-17}$. Our data showed that rosiglitazone had high affinities to OCT1 and OCT2, indicating that rosiglitazone may influence the body clearance of cationic drugs. It would be interesting to discover whether the inhibitory effect of rosiglitazone on the OCT transport function impacts the clinical setting. The pharmacokinetic of daily oral dose $(8 \mathrm{mg})$ of rosiglitazone in healthy volunteers showed that its maximum concentration in plasma was $2.2 \mu \mathrm{M}^{23}$. Because rosiglitazone binds to plasma protein by $99 \%$, the concentration of the 
unbound form of rosiglitazone was calculated to be about $22 \mathrm{nM}^{23}$. Although the concentration of rosiglitazone may not be high enough to inhibit the uptake of $\mathrm{MPP}^{+}$, which is a substrate with high affinity for OCT, at the rosiglitazone concentration of $20 \mathrm{nM}$ it may affect clearance of cationic drugs that have low affinity for OCT in clinical setting. Our unpublished data showed that the $\mathrm{IC}_{50}$ values of rosiglitazone for OCT1 and OCT2 were lower than that of metformin and metoprolol (metformin $>5 \mathrm{mM}$ for OCT1 and $1.2 \mathrm{mM}$ for OCT2; metoprolol were $86 \pm 7 \mu \mathrm{M}$ and $559 \pm 25 \mu \mathrm{M}$, respectively, unpublished data). These data indicated that rosiglitazone could decrease clearance of other cationic drugs. Rosiglitazone is metabolized by cytochrome P450 (CYP) $2 \mathrm{C}^{24}$, and the polymorphisms of this metabolizing enzyme have an impact on the plasma concentration of rosiglitazone ${ }^{25}$. The possibility that rosiglitazone may affect the pharmacokinetic of other cationic drugs may increase in patients who have low activity of this enzyme, or receive drug-induced enzyme inhibition such as gemfibrozil $^{26}$ and trimethoprim ${ }^{27}$ that increase the plasma level of rosiglitazone.

\section{CONCLUSIONS}

In summary, the present study demonstrated that rosiglitazone but not pioglitazone inhibited OCT1and OCT2-mediated transport of $\mathrm{MPP}^{+}$by a noncompetitive manner. The inhibitory effect of rosiglitazone may influence the pharmacokinetic of cationic drugs in patients who have polymorphism of CPY450 and during concomitant administration of CYP2C8 inhibitors.

Acknowledgements: This study project has been supported by grants from Centre of Excellence on Environmental Health and Toxicology, Science and Technology Postgraduate Education and Research Development Office (PERDO), Ministry of Education (to Sunhapas Soodvilai), Office of the Higher Education Commission and Mahidol University under the National Research Universities Initiative, and Faculty of Science, Mahidol University.

\section{REFERENCES}

1. Braunstein S (2003) New developments in type 2 diabetes mellitus: Combination therapy with a thiazolidinedione. Clin Therapeut 25, 1895-917.

2. Diamant M, Heine RJ (2003) Thiazolidinediones in type 2 diabetes mellitus: Current clinical evidence. Drugs 63, 1373-405.

3. Meriden T (2004) Progress with thiazolidinediones in the management of type 2 diabetes mellitus. Clin Therapeut 26, 177-90.
4. Chilcott J, Tappenden P, Jones ML, Wight JP (2001) A systematic review of the clinical effectiveness of pioglitazone in the treatment of type 2 diabetes mellitus. Clin Therapeut 23, 1792-823.

5. Wagstaff AJ, Goa KL (2002) Rosiglitazone: A review of its use in the management of type 2 diabetes mellitus. Drugs 62, 1805-37.

6. Cheng-Lai A, Levine A (2000) Rosiglitazone: An agent from the thiazolidinedione class for the treatment of type 2 diabetes. Heart Dis 2, 326-33.

7. Vasudevan AR, Balasubramanyam A (2004) Thiazolidinediones: A review of their mechanisms of insulin sensitization, therapeutic potential, clinical efficacy, and tolerability. Diabetes Tech Therapeut 6, 850-63.

8. Scheen AJ (2005) Drug interactions of clinical importance with antihyperglycaemic agents: An update. Drug Saf 28, 601-31.

9. Scheen AJ (2007) Pharmacokinetic interactions with thiazolidinediones. Clin Pharmacokinet 46, 1-12.

10. Wright SH, Dantzler WH (2004) Molecular and cellular physiology of renal organic cation and anion transport. Physiol Rev 84, 987-1049.

11. Kaewmokul S, Chatsudthipong V, Evans KK, Dantzler WH, Wright SH (2003) Functional mapping of rboct1 and rboct 2 activity in the 2 segment of rabbit proximal tubule. Am J Physiol Ren Physiol 285, F1149-59.

12. Inui KI, Masuda S, Saito H (2000) Cellular and molecular aspects of drug transport in the kidney. Kidney Int 58, 944-58.

13. Koepsell H, Lips K, Volk C (2007) Polyspecific organic cation transporters: Structure, function, physiological roles, and biopharmaceutical implications. Pharmaceut Res 24, 1227-51.

14. Motohashi H, Sakurai Y, Saito H, Masuda S, Urakami Y, Goto M, Fukatsu A, Ogawa O, Inui K (2002) Gene expression levels and immunolocalization of organic ion transporters in the human kidney. J Am Soc Nephrol 13, 866-74.

15. Bachmakov I, Glaeser H, Endress B, Morl F, Konig J, Fromm MF (2009) Interaction of beta-blockers with the renal uptake transporter oct2. Diabetes Obes Metabol 11, 1080-3.

16. Dudley AJ, Bleasby K, Brown CD (2000) The organic cation transporter oct 2 mediates the uptake of betaadrenoceptor antagonists across the apical membrane of renal llc-pk(1) cell monolayers. Br J Pharmacol 131, 71-9.

17. Kimura N, Masuda S, Tanihara Y, Ueo H, Okuda M, Katsura T, Inui K (2005) Metformin is a superior substrate for renal organic cation transporter oct 2 rather than hepatic oct1. Drug Metabol Pharmacokinet 20, 379-86.

18. Hayashi Y, Miyachi N, Takeuchi T, Takeuchi Y, Kamiya F, Kato $\mathrm{T}$, Imaeda $\mathrm{K}$, Okayama $\mathrm{N}$, et al (2003) Clinical evaluation of pioglitazone in patients with type 2 diabetes using alpha-glucosidase inhibitor and examination of its efficacy profile. Diabetes Obes 
Metabol 5, 58-65.

19. Harper JN, Wright SH (2013) Multiple mechanisms of ligand interaction with the human organic cation transporter, OCT2. Am J Physiol Ren Physiol 304, F56-67.

20. Hilgendorf C, Ahlin G, Seithel A, Artursson P, Ungell AL, Karlsson J (2007) Expression of thirty-six drug transporter genes in human intestine, liver, kidney, and organotypic cell lines. Drug Metabol Dispos 35, 1333-40.

21. Asavapanumas N, Kittayaruksakul S, Meetam P, Muanprasat C, Chatsudthipong V, Soodvilai S (2012) Fenofibrate down-regulates renal oct2-mediated organic cation transport via pparalpha-independent pathways. Drug Metabol Pharmacokinet 27, 513-9.

22. Sung JH, Yu KH, Park JS, Tsuruo T, Kim DD, Shim CK, Chung SJ (2005) Saturable distribution of tacrine into the striatal extracellular fluid of the rat: evidence of involvement of multiple organic cation transporters in the transport. Drug Metabol Dispos 33, 440-8.

23. Wittayalertpanya S, Chompootaweep S, Thaworn N, Khemsri W, Intanil N (2010) Pharmacokinetic and bioequivalence study of an oral $8 \mathrm{mg}$ dose of rosiglitazone tablets in thai healthy volunteers. J Med Assoc Thai 93, 722-8.

24. Baldwin SJ, Clarke SE, Chenery RJ (1999) Characterization of the cytochrome p450 enzymes involved in the in vitro metabolism of rosiglitazone. $\mathrm{Br} J$ Clin Pharmacol 48, 424-32.

25. Kirchheiner J, Thomas S, Bauer S, Tomalik-Scharte D, Hering U, Doroshyenko O, Jetter A, Stehle S, et al (2006) Pharmacokinetics and pharmacodynamics of rosiglitazone in relation to cyp2c8 genotype. Clin Pharmacol Therapeut 80, 657-67.

26. Niemi M, Backman JT, Granfors M, Laitila J, Neuvonen M, Neuvonen PJ (2003) Gemfibrozil considerably increases the plasma concentrations of rosiglitazone. Diabetologia 46, 1319-23.

27. Niemi M, Backman JT, Neuvonen PJ (2004) Effects of trimethoprim and rifampin on the pharmacokinetics of the cytochrome p450 2c8 substrate rosiglitazone. Clin Pharmacol Therapeut 76, 239-49. 